\title{
Problems in Ancient Literature Teaching and Countermeasures
}

\author{
Youjing Wang \\ Weinan Normal University, Weinan, Shaanxi, 714000, China
}

\begin{abstract}
Keywords: Ancient Chinese Literature; Problem Analysis; Teaching Reform
\end{abstract}
\begin{abstract}
Ancient Chinese literature is an indispensable part of the humanities and social sciences. It is also a compulsory course for the major of literature. Its main teaching goal is to improve students' humanities and comprehensive qualities, and to realize the all-round development of students. Ancient Chinese literature is a highly comprehensive discipline. It can be said that he contains all the outstanding cultural spirits in our country from ancient times to today. It is a discipline that pays equal attention to both history and literature. It is not only the accumulation of culture but also the spiritual inheritance, so through the teaching of ancient literature can enhance the spiritual conservation of students, consolidate its cultural foundation. However, with the increasing openness of the society, the ancient Chinese literature in the higher education is getting less and less attention, leading to many problems in the actual teaching process. The article mainly analyzes the existing problems in ancient Chinese literature teaching and puts forward specific solutions.
\end{abstract}

\section{The Problems of Ancient Chinese Literature Teaching}

Ancient Chinese literature covers many contents and is open for a long time, which contains the essence of the Chinese nation. By studying this course, it can enhance students' national pride and promote the carrying forward and inheriting of the national spirit. However, in practical teaching, there are still some problems in the following aspects:

Ancient Chinese literature contains literary works and ideological connotations accumulated over the past thousands of years in our country. Many ancient documents seem to have nothing to do with modern life. Students not only understand difficulties, but also think that these ancient poems and literatures are "useless" After all, ancient literature does not seem "useful" as other technical majors do. Therefore, students generally have a low interest in learning ancient Chinese literature. Even some Chinese majors do not read important classics such as The Analects and do not have complete reading There are also four famous people. Teachers teach knowledge in the classroom, students can only take notes in a limited class, rather than reading a lot to appreciate the meaning of ancient Chinese literature, the long run, students will only rote and can not form a profound understanding of national culture.

At present, most ancient Chinese literature in ancient Chinese literature or the ancient literary history is the main, but the study of literary history actually belongs to the category of cultural studies. And the traditional view of university curriculum in our country is formed in the specific historical background. The setting of professional curriculum is based on social standard. The value orientation of education also focuses on the training of senior professionals, emphasizing the practicality of personnel training. However, with the continuous improvement of society, the continuous updating and reform of educational values and educational concepts, the teaching materials compiled under the influence of personnel training are outdated and obsolete. Take the most typical example, when explaining "A Dream of Red Mansions", many textbooks also stress that Lin Daiyu is a revolt of the feudal social thought, and Xue Baochai is the representative of the feudal rule. In fact, it is impossible for Cao Xueqin in the Qing Dynasty to have the idea of "feudal society" Concept, so the textbook theory is obviously a misunderstanding of the original, the students' understanding of "Dream of Red Mansions" will be misleading.

Chinese language major is also an important content of the curriculum reform. After the reform of the new curriculum, the ancient literature curriculum also followed the adjustment, the most 
obvious is the shortening of the class time. On the one hand, the school believes that the ancient literature course is a basic course, which is of less importance than other major courses of the Chinese language. On the other hand, the important role of ancient literature was not fully recognized, so the class time of ancient literature teaching was short. However, in the actual teaching, since ancient literature involves the knowledge content of our country up and down for thousands of years, its contents are wide and the time span is long, so it contains rich knowledge points. For example, the teaching of ancient literature, which is closely related with the literary works in the pre-Qin period, such as the "Book of Songs", "Chu Ci" and so on, of which only the "Book of Songs" occupy a large proportion of shortening the class after both teachers and students accept It is a challenge that the teachers' time to conduct in-depth analysis of literary works is short, which directly leads to the lack of literary teaching and ultimately the quality of teaching.

\section{The Strategy to Improve the Quality of Ancient Chinese Literature Teaching}

In view of the problems existing in ancient Chinese literature teaching, it is suggested to improve from the following aspects:

Curriculum reform is the core theme of education. The reform of textbooks is also the focus of curricular reform. Therefore, we need to explore a textbook that is in line with the needs of the times. In the exploration of new teaching materials, we should pay attention to two aspects. On the one hand, we must establish a correct and unified teaching material core values. Writing textbooks should be consistent with the essential characteristics of ancient literature, combined with the characteristics of higher education, not only to emphasize the accumulation of college students knowledge, but also pay attention to the innovation and heritage of national culture. On the other hand, in the process of concrete compilation, ancient literature can not only stay in the narrow concept, but emphasize a broad sense of ancient literature, and compile the literary connotation of literary works in the textbooks instead of intercepting only a part of the contents to mislead the students. And, the contents of the ideological content of the work should be consistent with the development of the times and the eternal truth, kindness and beauty of mankind should be explored. In selecting a specific work, in addition to preserving the original poems, prose, opera, novels, but also add some essays, official documents, letters, etc; even before we are not recognized by the "Times", making ancient literature teaching materials and Ancient literature is closer, enabling students to more fully touch ancient literature, heritage, and carry forward the outstanding achievements of the Chinese nation.

The ancient literature is usually subdivided into two categories: the history of ancient literature and literary works. The courses are large in volume but less in class hours. If the contradictions are to be reasonably adjusted, the following must be done: First, teachers should continuously improve their literary accomplishments and comprehensive qualities, ancient literature is huge and complicated. Teachers must have rich practical experience in order to make a reasonable choice of teaching content in the classroom, grasp the focus of classroom teaching, and deliver the essence of more knowledge to students in a limited time. Second, arrange homework reasonably. Extracurricular assignments have always been an extension and supplement of limited classroom teaching time. Through extracurricular homework teachers can keep abreast of the mastery of students' knowledge points and students can consolidate knowledge through extracurricular assignments. However, teachers should pay attention to the effectiveness of homework assignments and design more practical exercises to reinforce the students' reviewing results. For example, teachers can use the campus network resources to create public numbers, online forums and so on, through the network of students preview, guidance, students can also provide homework through the network, share learning experience, and even try to poetry autonomy, etc., and students in the network Activities can directly record the assessment system. This method can make up for the lack of class time to the maximum extent, and retain sufficient energy to understand students under dynamic learning situation, improve teaching effectiveness. 


\subsection{Enhance teacher-student interaction in classroom teaching.}

During the teaching process, teachers should consciously enhance their interaction with students, choose what students are more interested in. Students should come to power according to their own understandings. Teachers should listen to other students and give guidance on what the students are saying. This approach can often get better results. On the one hand, students must make adequate preparations before going to the stage to explain. Like the teachers preparing lessons, they collect information and enrich the handouts. The whole process requires students to continuously learn and accept new knowledge, and their ability to analyze and solve problems will also increase. On the other hand, the role of teacher and student exchange can also enable students to experience the hardships of teachers in the classroom lectures, teachers can also experience the psychological feelings of students listening, help teachers and students understand each other, mutual understanding, closer to teachers and students the distance between.

\subsection{To guide students to participate in the study of ancient literature through debating contests and discussion classes.}

To some extent, the main content of Chinese ancient literature courses is nothing more than the author, works, literary thoughts, the law of development and other content, some content of students too much contact will inevitably produce a sense of boring. In response to this problem, teachers can bother to design some debating topics or topics for discussion in the classroom. They can conduct open teaching in the classroom and guide students to actively participate in classroom teaching so as to enhance students' subjective initiative in learning and A sense of participation The topics discussed may be the hot topics of academic concern, or set general questions according to the content of the textbooks. Students should be asked to form their own basic views through reading and collecting materials no matter what kind of problems they are facing. Through discussion sessions and debate contests, Express your own opinion.

The traditional assessment method is nothing more than a regular examination of papers. This single assessment model only focuses on students' knowledge of the degree of mastery, ignoring the evaluation of the ability of students to improve, there is a problem with the results of the light process, the students The evaluation is not comprehensive enough and objective, resulting in students' attitude toward learning there are deviations, and students can not learn by rote learning to use, so to improve the traditional assessment methods, not only to focus on the assessment results , But also apply Formative Assessment to evaluate students' learning process. The new curriculum reform emphasizes the cultivation of students' comprehensive qualities, humane qualities and innovative abilities. Therefore, assessment and evaluation also emphasize the quality of students and their abilities. They should pay attention to the learning process of students and increase the proportion of their usual achievements. For the study of Chinese ancient literature courses, the old students need to analyze students' ability of writing and writing, try to reduce the proportion of knowledge-based topics to guide students to take the initiative to explore and develop open-minded thinking. Daily study should focus on poetry, novels, dramas and other literary works to read and appreciate, provides a certain number of recitation of the text, increase the amount of reading students. Through reading and annotating works, students can deepen their cognition of literary history and enhance their ability to interpret ancient Chinese literatures. In addition, students should express their opinions on interactive platform of teachers and students, or submit small research papers, sentiment about works, discuss with students 'teachers on relevant issues, make up class hours according to students' speeches, quality of papers, etc.

\section{Conclusion}

In short, in the course of teaching reform in ancient Chinese literature, we must fully exploit the rich resources therein, embody the spiritual connotation of the Chinese nation and seek opportunities to transform the ancient excellent culture into modern civilization. We also put these energetic knowledge contents Pass on to students, improve their cultural accomplishment and 
perfect their personality traits. Of course, in the process of actual reform, we must fully recognize the importance of Chinese ancient literature courses, arrange class hours reasonably, reform teaching materials, improve teaching methods, and ensure that the content of course teaching goes with the times. Through ample demonstration of practice we can improve the effectiveness of ancient literature teaching.

\section{Acknowledgements}

Fund Project: Weinan Teachers College Teaching Reform Project: Yuan Ming and Qing Opera "Student Appreciation Ability Research (JG201659)

\section{References}

[1] Zhou Jianhua. College Chinese ancient literature teaching reform problems [J]. Education and Careers, 2014,08: 141-142.

Journal of Yangtze University (Social Science Edition), 2014,01: 163-164. [2] Dong Suzhen. Problems in ancient literature teaching and reform strategies [J].

[3] Jin Yanxia. Some Thoughts on the Reform of Ancient Literature Teaching Idea [J]. Journal of Gansu Lianhe University (Social Sciences Edition), 2017,05: 107-111.

[4] Zheng Sheng. Re-examine the concept of Chinese ancient literature teaching [J]. Yuxi Teachers' College Journal, 2016,11: 47-50.

[5] Sun Yubing. Problems in the teaching of ancient Chinese literature and its reform [J]. Journal of Qinghai Normal University (Philosophy and Social Sciences), 2016,05: 134-137.

[6] Li Xinyu on the ancient Chinese literature teaching problems and strategies [J]. Xinzhou Teachers College, 2016,06: 96-98. 